\title{
A new method for high-resolution characterization of hydraulic conductivity
}

\author{
Gaisheng Liu, ${ }^{1}$ James J. Butler Jr., ${ }^{1}$ Geoffrey C. Bohling, ${ }^{1}$ Edward Reboulet, ${ }^{1}$ \\ Steve Knobbe, ${ }^{1}$ and David W. Hyndman ${ }^{2}$ \\ Received 22 June 2009; accepted 20 July 2009; published 29 August 2009.
}

[1] A new probe has been developed for high-resolution characterization of hydraulic conductivity $(K)$ in shallow unconsolidated formations. The probe was recently applied at the Macrodispersion Experiment (MADE) site in Mississippi where $K$ was rapidly characterized at a resolution as fine as $0.015 \mathrm{~m}$, which has not previously been possible. Eleven profiles were obtained with $K$ varying up to 7 orders of magnitude in individual profiles. Currently, high-resolution $(0.015-\mathrm{m})$ profiling has an upper $K$ limit of $10 \mathrm{~m} / \mathrm{d}$; lower-resolution $(\approx 0.4-\mathrm{m})$ mode is used in more permeable zones pending modifications. The probe presents a new means to help address unresolved issues of solute transport in heterogeneous systems.

Citation: Liu, G., J. J. Butler Jr., G. C. Bohling, E. Reboulet, S. Knobbe, and D. W. Hyndman (2009), A new method for high-resolution characterization of hydraulic conductivity, Water Resour. Res., 45, W08202, doi:10.1029/2009WR008319.

\section{Introduction}

[2] Spatial variations in hydraulic conductivity $(K)$ play an important role in subsurface transport [e.g., Gelhar and Axness, 1983; Dagan, 1989; Dagan and Neuman, 1997; Harvey and Gorelick, 2000; Berkowitz et al., 2006]. A major research challenge has been to develop field methods that allow $K$ information to be obtained at the resolution needed to quantify solute movement in heterogeneous formations, as current state-of-the-practice methods have proven to be of limited effectiveness for this purpose [Butler, 2005].

[3] Direct-push methods have shown much promise for characterizing $K$ in shallow unconsolidated formations [Hinsby et al., 1992; Lunne et al., 1997; McCall et al., 2005; Sellwood et al., 2005]. Recently, two tools, the directpush permeameter (DPP) and the direct-push injection logger (DPIL), have been developed and demonstrated in controlled field settings [Butler et al., 2007; Dietrich et al., 2008]. The DPP is a small-diameter tool with a short cylindrical screen and two pressure transducers set into a direct-push rod [Lowry et al., 1999; Butler et al., 2007]. A series of injection tests are performed at a given depth and $K$ is estimated from the test data. The resulting estimate is a weighted average over the interval $(0.367 \mathrm{~m}$ in current tool) between the screen and the farthest transducer [Liu et al., 2008]. Material outside of that interval has little influence, resulting in significant uncertainty about conditions between test intervals. Although the DPP is much more time-efficient than other approaches (e.g., slug tests), each test sequence still requires $10-15 \mathrm{~min}$ in moderate to high- $K$ intervals [Butler et al., 2007]. The time required for a test sequence,

\footnotetext{
${ }^{1}$ Kansas Geological Survey, University of Kansas, Lawrence, Kansas, USA

${ }^{2}$ Department of Geological Sciences, Michigan State University, East Lansing, Michigan, USA.
}

Copyright 2009 by the American Geophysical Union. 0043-1397/09/2009WR008319 coupled with the volumetric averaging of the tool, currently limits DPP resolution to $\approx 0.4 \mathrm{~m}$ in most cases.

[4] The DPIL consists of a single screened port on a direct-push rod [Dietrich et al., 2008]. Water is injected through the screen while the pressure response is monitored behind the screen or at the surface. The injection logging process can be conducted continuously as the tool is advanced or in a discontinuous mode where advancement is briefly halted while the injection rate is varied in a stepwise fashion. The profile of the ratio of injection rate to pressure reflects vertical variations in $K$. The DPIL continuous advancement mode provides rapid and detailed, but qualitative, $K$ information (a $10-\mathrm{m}$ profile at $0.015-\mathrm{m}$ resolution typically takes $<30 \mathrm{~min}$ ). Methods are needed for transforming the DPIL ratios into $K$ estimates [Dietrich et al., 2008].

[5] We coupled the DPP and DPIL into a single probe, called the high-resolution $K$ (HRK) tool (Figure 1), to better realize the potential of these probes. This new tool, which has the external appearance of the DPP, is designed so that water can be injected through both transducer ports and the injection screen during advancement. Injection rates and pressure responses are monitored continuously during advancement, i.e., the tool functions in continuous DPIL mode. Upon reaching a test depth, advancement ceases and DPP injection tests are performed. The DPP test data are then used to transform the high-resolution DPIL information into $K$ estimates. In this paper, we describe the procedures and the results of an initial field application of the HRK tool.

\section{Field Application Overview}

[6] The HRK tool was applied at the extensively studied Macrodispersion Experiment (MADE) site on Columbus Air Force Base in Mississippi, United States (Figure 2). The shallow unconfined aquifer at the site consists of unconsolidated fluvial terrace deposits with an average thickness of $11 \mathrm{~m}$. The major permeable unit is composed of poorly to 


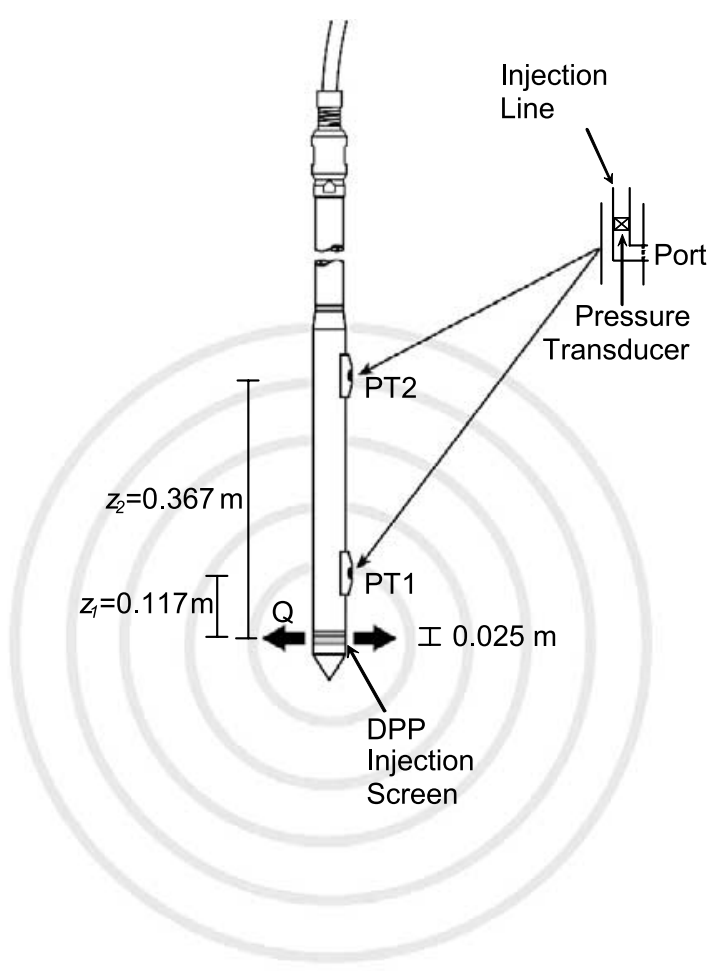

Figure 1. Schematic of the high-resolution $K$ (HRK) tool (modified from Butler et al. [2007]). Gray circles qualitatively illustrate equipotentials produced by injection through the DPP screen in a homogeneous, isotropic aquifer. During advancement, water is injected through the injection screen and transducer ports. The DPP tool has a similar appearance but does not have injection lines at the transducer ports. The DPIL tool used in continuous advancement mode has a single transducer-injection port at PT2. The prototype HRK tool used in this work was constructed by Geoprobe Systems of Salina, Kansas.

well sorted sand and gravel with small amounts of silt and clay, overlain by overbank and channel deposits of a meandering fluvial system and underlain by fine marine sediments of the Eutaw Formation [Boggs et al., 1992]. The results from three major natural gradient tracer tests at the site (MADE-1, MADE-2 and MADE-3; see Zheng [2006] for a review) have stimulated widespread discussion on the fundamental limitations of site characterization methods and solute transport modeling in highly heterogeneous aquifers.

[7] In November 2008, 11 HRK profiles were obtained in two areas (MLS and ICA cubes on Figure 2) of the MADE site. Figure 3 a shows an example sequence of DPP tests. Upon reaching the test depth, advancement and injection ceased. Once pressures at both transducers had recovered, the injection test began. Three tests were performed at each location to assess the reliability of the DPP $K$ estimates; the observed pressure responses determined how the injection rate should be varied for the next test in the sequence. The $K$ estimates (note the consistency in estimates in Figure 3a; a lack of consistency could indicate sensor instability or formation alteration) were calculated using Darcy's law [Butler et al., 2007]. After testing was completed, the tool was advanced to the next depth. During that advancement, DPIL data were continuously collected at both transducer locations. A similar procedure was followed for all 11 profiles.

[8] Figure $3 b$ shows the DPIL injection rates, injectioninduced pressures, and injection rate/pressure ratios for profile 131108A. The injection rate and pressure were measured every $0.015 \mathrm{~m}$ as the tool was advanced at $\approx 0.02 \mathrm{~m} / \mathrm{s}$. In order to develop a relationship that can also be used with a DPIL-only tool, the focus here is on the data from the top transducer (PT2 in Figure 1), which is the furthest from the DPP screen (thus minimizing the influence of the DPP screen injection). The injection-induced pressure was calculated by subtracting the assumed hydrostatic background pressure from the pressure measured during advancement. The assumption of hydrostatic background pressure was verified using pressures collected immediately prior to start of injection at each DPP test depth, and hydrostatic pressure was linearly interpolated between these depths. The ratio of injection rate to pressure (Figure $3 b$ ) indicates considerable heterogeneity within the aquifer $(3.6-12 \mathrm{~m})$ with a zone of relatively low $K$ near the center $(7.5-9.0 \mathrm{~m})$. Note the large pressure increase when the tool reaches the Eutaw Formation at about $12 \mathrm{~m}$ depth.

\section{Data Analysis}

[9] The central idea of the HRK tool is to transform the qualitative DPIL injection rate/pressure profiles into highresolution $K$ estimates using a power law transformation,

$$
K=10^{b}(D P I L)^{a}, \text { or } \log _{10}(K)=a \log _{10}(D P I L)+b,
$$

where $a$ and $b$ are coefficients whose values are determined through calibration. Initial estimates of the coefficients are used to generate $K$ profiles that are input into a numerical model that simulates DPP test responses for each profile. Rather than trying to match the DPP responses for each profile separately, the coefficients were adjusted to produce the best match between observed and simulated responses over the entire set of DPP tests performed at the site. This is somewhat similar to the approach of correlating DPIL ratios with $K$ estimates from other methods [Dietrich et al., 2008]. However, in this work the DPP and DPIL data are collocated so we are matching DPP pressure data to responses simulated with transformed DPIL data from the same borehole, instead of developing correlations with $K$ data collected nearby (thereby eliminating concerns about comparing $K$ at different scales and locations).

[10] The DPP tests from the 11 HRK profiles (53 test depths with one test per depth) were simulated using the cylindrical coordinate finite difference model lr2dinv [Bohling and Butler, 2001]. Assuming angular symmetry, lr2dinv solves the steady state flow equation, which is also applicable under the steady shape (hydraulic gradient not changing with time; Butler et al. [2007]) conditions rapidly obtained in a DPP test (Figure 3a),

$$
\frac{1}{r} \frac{\partial}{\partial r}\left(r K_{r} \frac{\partial h}{\partial r}\right)+\frac{\partial}{\partial z}\left(K_{z} \frac{\partial h}{\partial z}\right)=0,
$$

where the head $h$ is a function of the radial coordinate $r$, vertical coordinate $z ; K_{r}$ and $K_{z}$ are the radial and vertical components of hydraulic conductivity, respectively. 


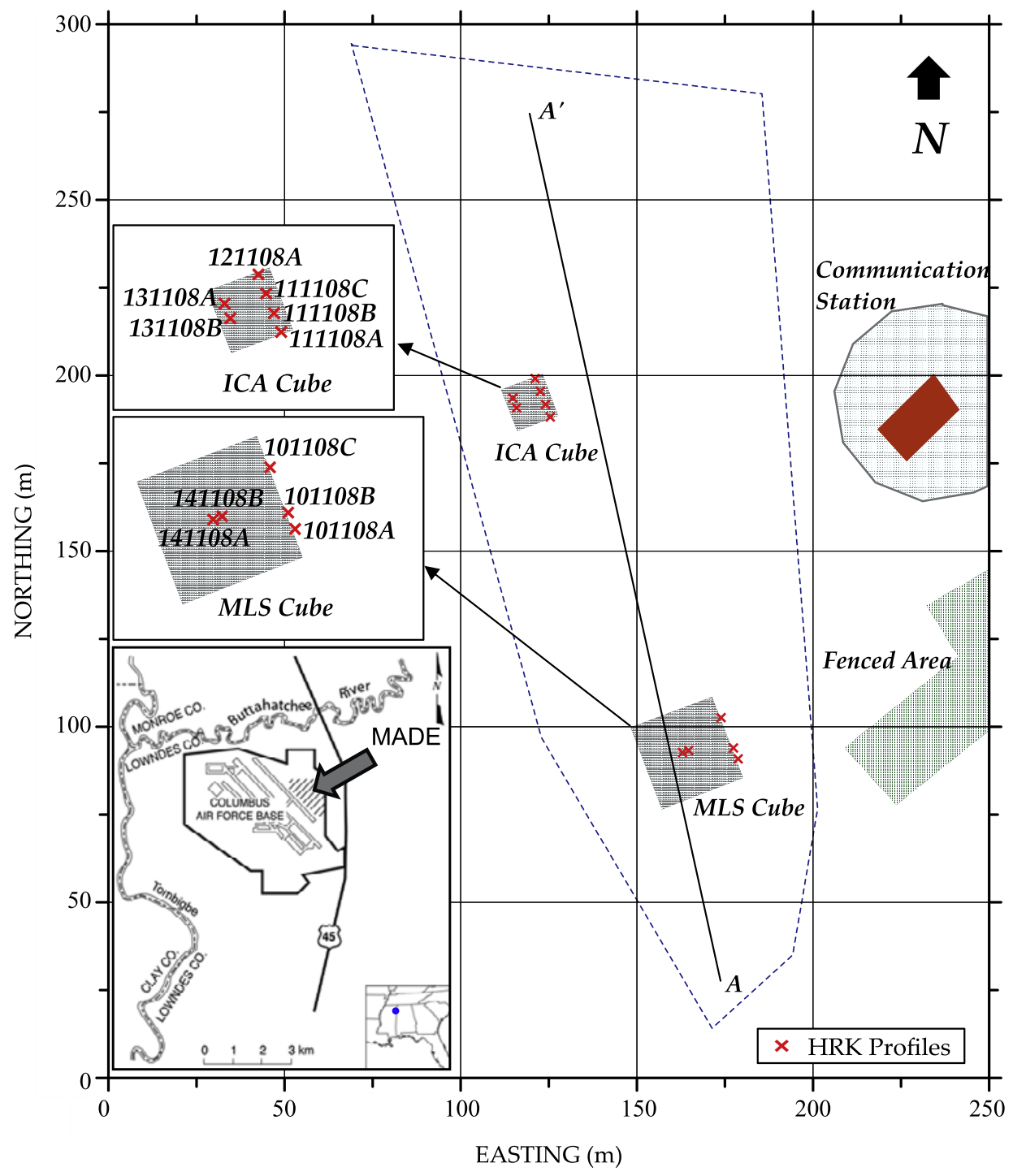

Figure 2. HRK profiles at the MADE site. Line $A-A^{\prime}$ approximately follows the centerline of the MADE-2 plume. The dashed line represents the boundary of the sampling network during the MADE-2 test (network no longer exists). The ICA cube is the site of previous intensive coring activity, while the MLS cube is the location of a previous dual-well tracer test monitored with multilevel samplers. 
(a) DPP data from profile $131108 \mathrm{~A}$

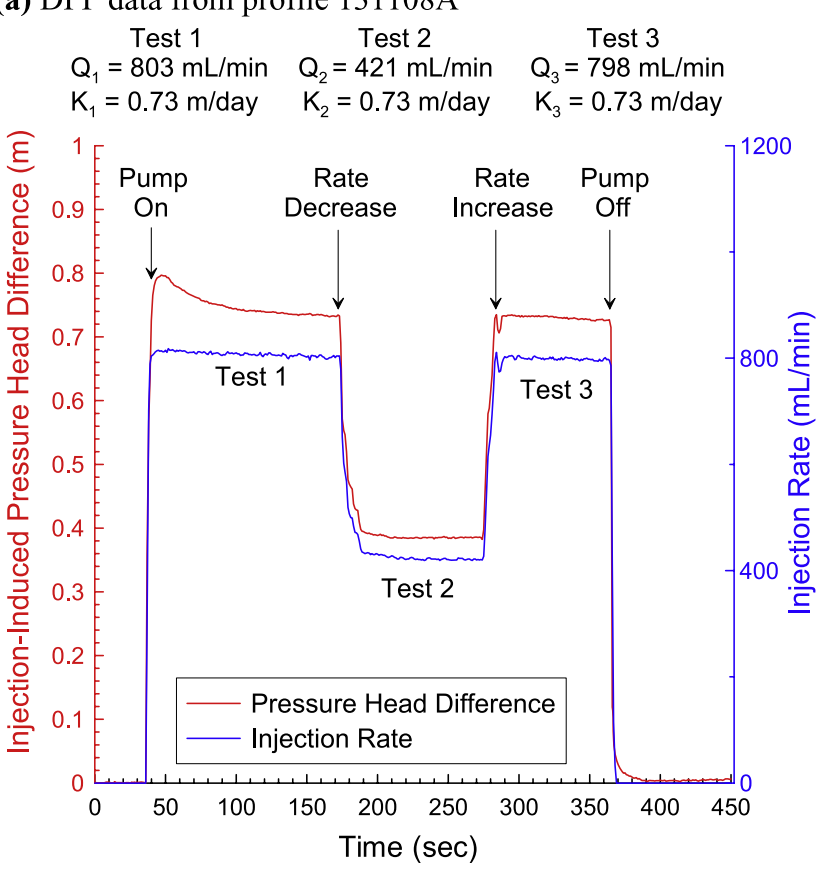

(b) DPIL data from profile $131108 \mathrm{~A}$

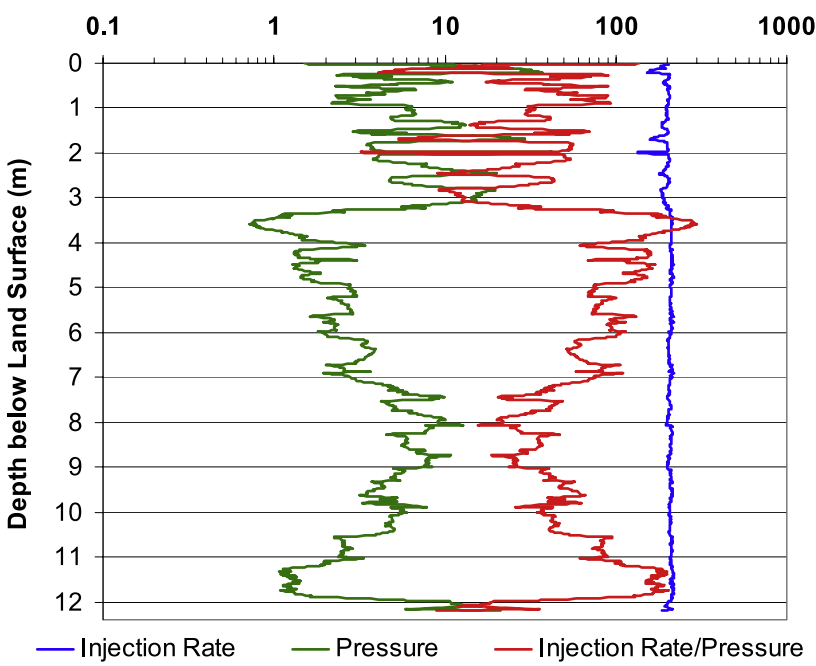

Figure 3. Example DPP and DPIL data: (a) DPP injection rate and pressure head difference between the transducers versus time at depth $10.67 \mathrm{~m}$ (depth is the midpoint between transducers; zero time is at the start of logging for that depth) and (b) DPIL injection rate ( $\mathrm{mL} / \mathrm{min})$, injectioninduced pressure head $(\mathrm{m})$, and the injection rate/pressure head ratio $(\mathrm{mL} / \mathrm{min} / \mathrm{m})$ versus depth.

[11] The inner boundary condition at $r=r_{w}$, where $r_{w}$ is the tool radius $(0.0225 \mathrm{~m})$, is zero flow except at the injection screen. The outer boundary condition at $r=r_{o}$, where $r_{o}$ is the distance from tool center to model edge $(40 \mathrm{~m})$, is constant head.

[12] Each HRK profile was simulated using a grid of 551 layers and 42 cylindrical columns. All layers were $0.015 \mathrm{~m}$ thick so that the DPIL data could be directly incorporated into the model; each layer was assumed to be isotropic and homogeneous in $K$. The radial distance between the tool center and that of each column increased exponentially to allow more detail near the tool.

\section{Results and Discussion}

[13] Figure 4 shows $K$ estimates calculated from the DPIL ratios using (1), along with $K$ values computed analytically from the DPP tests [Butler et al., 2007]. The calibrated values of $a$ and $b$ were determined to be 2.5 and -9.0 , respectively. The root-mean-square residual (RMS) between the log-transformed simulated and observed injection-induced head differences for all 11 profiles (53 DPP tests) is 0.70. The log transform was used to give similar weighting to large head differences in low- $K$ zones and small differences in high- $K$ zones. At 16 DPP depth intervals, there was an inconsistency in $K$ estimates between tests due to sensor instability or formation alteration. Excluding those intervals did not change the values of $a$ and $b$, but lowered the RMS to 0.51 .

[14] Profiles 101108A-C and 141108A-B were performed in the MLS cube, while the other profiles were in the ICA cube (Figure 2). DPIL $K$ estimates vary from less than 0.0001 to $10 \mathrm{~m} / \mathrm{d}$ in individual profiles (Figure 4), demonstrating the high degree of heterogeneity at the site. In the MLS cube, there is a consistent high- $K$ upper zone. The depth of the transition to lower $K$ intervals varies $(5.8-8.5 \mathrm{~m})$ between profiles. In the ICA cube, there are high- $K$ intervals in both upper and lower portions of the aquifer.

[15] DPIL-transformed $K$ estimates are generally in good agreement with the DPP estimates below $10 \mathrm{~m} / \mathrm{d}$. However, in profiles $141108 \mathrm{~A}$ and $141108 \mathrm{~B}$, the DPP $K$ estimates for a number of intervals exceed $100 \mathrm{~m} / \mathrm{d}$, while the DPIL $K$ estimates do not increase above $10 \mathrm{~m} / \mathrm{d}$. This insensitivity of DPIL estimates to high- $K$ zones is primarily due to our inability to obtain measurable formation responses in those zones because the transducer port losses greatly exceeded injection-induced formation pressures. We anticipate that the range of DPIL estimates can be extended by modifying the ports on the prototype probe to diminish losses, accurately characterizing those losses, and/or using higher injection rates during advancement. In the absence of such modifications, $K$ estimates for the higher- $K$ zones can only be obtained with the DPP. Given the time required for a DPP test sequence and the volumetric averaging inherent in the DPP, the finest vertical resolution of the HRK tool in higher- $K$ zones will typically be $\approx 0.4 \mathrm{~m}$.

\section{Conclusions}

[16] In this paper, we introduce a new probe for characterizing vertical $K$ variations in shallow unconsolidated aquifers, the high-resolution $K$ (HRK) tool, that is the result of coupling the recently developed direct-push permeameter (DPP) and the direct-push injection logger (DPIL) into a single unit. This HRK tool, which allows $K$ estimates to be obtained at a vertical resolution as fine as $0.015 \mathrm{~m}$, was applied at the highly heterogeneous MADE site. A single power law relationship was developed to transform the qualitative DPIL injection rate/pressure ratios collected during probe advancement into $K$ values for all 11 profiles from the site. The transformed values were consistent with estimates from DPP tests in intervals where $K$ is less than $10 \mathrm{~m} / \mathrm{d}$. In more permeable zones, the injection rates used 


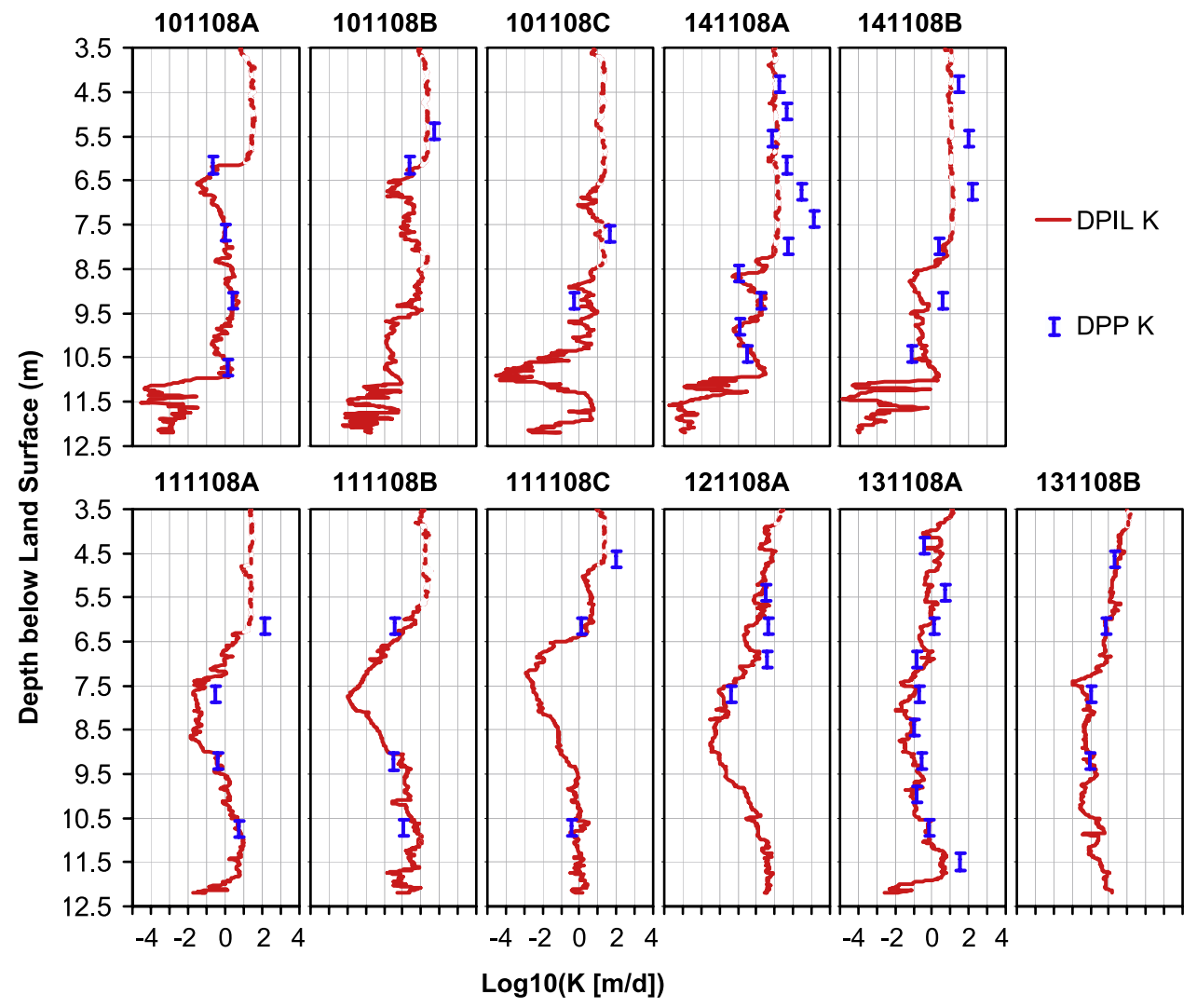

Figure 4. $K$ estimates calculated from the DPIL injection rate/pressure ratios using equation (1) compared to DPP $K$ values determined using Darcy's law. The DPP K values are averaged over 0.4-m depth intervals (represented by the vertical bars). The upper limit for the DPIL $K$ values is about 10 $\mathrm{m} / \mathrm{d}$, most evident in profiles 141108A-B. The DPIL $K$ values above that threshold are plotted as dashed lines. Depth of static water level is $3.6 \mathrm{~m}$ for MLS cube and $3.9 \mathrm{~m}$ for ICA cube.

during advancement could not produce measurable pressure responses with the prototype tool configuration and profiling procedure, thereby limiting profiling to lower-resolution DPP mode $(\approx 0.4 \mathrm{~m})$. Modifications are needed to extend the upper $K$ limit for high-resolution $(0.015 \mathrm{~m})$ profiling in highly permeable settings. This initial study demonstrates the power of the HRK tool to rapidly characterize $K$ variations at a resolution that has not previously been possible, providing a new means to address unresolved issues of subsurface solute transport in highly heterogeneous systems.

[17] Acknowledgments. This work was supported by the Hydrologic Sciences Program of the National Science Foundation (grants EAR0738955 and EAR-0738938). Any opinions, findings, and conclusions or recommendations expressed are those of the authors and do not necessarily reflect the views of the NSF. We thank Thomas Vienken and Uwe Schneidewind of UFZ-Leipzig, Geoffrey Tick of the University of Alabama, and Shane Reed of Columbus Air Force Base for their assistance. Geoprobe Systems of Salina, Kansas, constructed the prototype HRK tool used in this work.

\section{References}

Berkowitz, B., A. Cortis, M. Dentz, and H. Scher (2006), Modeling nonFickian transport in geological formations as a continuous time random walk, Rev. Geophys., 44, RG2003, doi:10.1029/2005RG000178.

Boggs, J. M., S. C. Young, L. M. Beard, L. W. Gelhar, K. R. Rehfeldt, and E. E. Adams (1992), Field study of dispersion in a heterogeneous aquifer: 1. Overview and site description, Water Resour. Res., 28(12), 32813291, doi:10.1029/92WR01756.
Bohling, G. C., and J. J. Butler Jr. (2001), Lr2dinv: A finite-difference model for inverse analysis of two-dimensional linear or radial groundwater flow, Comput. Geosci., 27(10), 1147-1156, doi:10.1016/S00983004(01)00036-X.

Butler, J. J., Jr. (2005), Hydrogeological methods for estimation of hydraulic conductivity, in Hydrogeophysics, Water Sci. Technol. Libr., vol. 50, edited by Y. Rubin and S. Hubbard, pp. 23-58, Springer, Dordrecht, Netherlands.

Butler, J. J., Jr., P. Dietrich, V. Wittig, and T. Christy (2007), Characterizing hydraulic conductivity with the direct-push permeameter, Ground Water, 45(4), 409-419, doi:10.1111/j.1745-6584.2007.00300.x.

Dagan, G. (1989), Flow and Transport in Porous Formations, 465 pp., Springer, New York.

Dagan, G., and S. P. Neuman (1997), Subsurface Flow and Transport: A Stochastic Approach, Cambridge Univ. Press, Cambridge, U. K.

Dietrich, P., J. J. Butler Jr., and K. Faiß (2008), A rapid method for hydraulic profiling in unconsolidated formations, Ground Water, 46(2), 323-328, doi:10.1111/j.1745-6584.2007.00377.x.

Gelhar, L. W., and C. L. Axness (1983), Three-dimensional stochastic analysis of macrodispersion in aquifers, Water Resour. Res., 19(1), 161-180, doi:10.1029/WR019i001p00161.

Harvey, C. F., and S. M. Gorelick (2000), Rate-limited mass transfer or macrodispersion: Which dominates plume evolution at the Macrodispersion Experiment (MADE) site?, Water Resour. Res., 36(3), 637-650, doi:10.1029/1999WR900247.

Hinsby, K., P. L. Bjerg, L. J. Andersen, B. Skov, and E. V. Clausen (1992), A mini slug test method for determination of a local hydraulic conductivity of an unconfined sandy aquifer, J. Hydrol., 136(1-4), 87-106, doi:10.1016/0022-1694(92)90006-H.

Liu, G., G. C. Bohling, and J. J. Butler Jr. (2008), Simulation assessment of the direct-push permeameter for characterizing vertical variations in hydraulic conductivity, Water Resour. Res., 44, W02432, doi:10.1029/ 2007WR006078. 
Lowry, W., N. Mason, V. Chipman, K. Kisiel, and J. Stockton (1999), In-situ permeability measurements with direct push techniques: Phase II topical report, Rep. SEASF-TR-98-207, 102 pp., Fed. Energy Technol. Cent., Dep. of Educ., Morgantown, W. Va.

Lunne, T., P. K. Robertson, and J. J. M. Powell (1997), Cone Penetration Testing in Geotechnical Practice, Blackie Acad. Prof., London.

McCall, W., D. M. Nielsen, S. Farrington, and T. C. Christy (2005), Use of direct-push technologies in environmental site characterization and ground-water monitoring, in The Practical Handbook of Environmental Site Characterization and Ground-Water Monitoring, 2nd ed., edited by D. M. Nielsen, pp. 345-472, CRC Press, Boca Raton, Fla.

Sellwood, S. M., J. M. Healey, S. Birk, and J. J. Butler Jr. (2005), Directpush hydrostratigraphic profiling: Coupling electrical logging and slug tests, Ground Water, 43(1), 19-29, doi:10.1111/j.1745-6584.2005. tb02282.x.
Zheng, C. (2006), Accounting for aquifer heterogeneity in solute transport modeling: A case study from the macrodispersion experiment (MADE) site in Columbus, Mississippi, in Handbook of Groundwater Engineering, 2nd ed., edited by J. W. Delleur, pp. 26-1-26-18, CRC Press, Boca Raton, Fla.

G. C. Bohling, J. J. Butler Jr., S. Knobbe, G. Liu, and E. Reboulet, Kansas Geological Survey, University of Kansas, 1930 Constant Avenue, Lawrence, KS 66047-3726, USA. (gliu@kgs.ku.edu)

D. W. Hyndman, Department of Geological Sciences, Michigan State University, 206 Natural Science Building, East Lansing, MI 48824-1115, USA. 